\title{
Comprehensive evaluation and validation of targeted next-generation sequencing performance in two clinical laboratories
}

\author{
PEDRO MENDEZ ${ }^{1,2}$, JENNIFER DANG $^{3}$, JAMES WANSOO KIM $^{3}$, SHARON LEE $^{3}$, JUN-HEE YOON $^{1,2}$, \\ THOMAS KIM ${ }^{3}$, CHARLES J. SAILEY ${ }^{3,4}$, DAVID M. JABLONS ${ }^{1,2}$ and IL-JIN KIM ${ }^{1,2}$
}

${ }^{1}$ Thoracic Oncology Laboratory, Department of Surgery, ${ }^{2}$ Comprehensive Cancer Center, University of California San Francisco, San Francisco, CA 94115; ${ }^{3}$ CureSeq Inc., Brisbane, CA 94005; ${ }^{4}$ Purity Laboratories, Lake Oswego, OR 97035, USA

Received February 23, 2016; Accepted April 6, 2016

DOI: 10.3892/ijo.2016.3497

\begin{abstract}
Next-generation sequencing (NGS) has led to breakthroughs for genetic and genomic analyses and personalized medicine approaches for many diseases. More and more clinical laboratories are using NGS as a genetic screening tool for providing mutation information that is used to select the best treatment regimens for cancer patients. However, several obstacles prevent the routine implementation of NGS technology into the clinical molecular diagnosis setting: the sophisticated sample preparation process, high cost, timeconsuming data analyses, as well as the reproducibility and accuracy of interpretation. To systematically evaluate the performance and quality of targeted NGS cancer panel analyses in clinical laboratories, we performed three different tests: i) laboratory-to-laboratory accuracy test, ii) intra-laboratory precision validation, and iii) limit of detection test, using formalin-fixed, paraffin-embedded cancer tissue specimens, cell lines and mutation positive DNA. A laboratory-to-laboratory accuracy test performed using 51 samples showed $100 \%$ sensitivity and $99.97 \%$ specificity. For the intra-laboratory precision test, $100 \%$ reproducibility was observed. For the limit of detection test, KRAS mutations from samples diluted from 70 to $2 \%$ of mutant allele frequencies were detected correctly. We believe that the present study demonstrated the feasibility of clinical implementation of a targeted NGS cancer panel analysis for personalized medicine.
\end{abstract}

\section{Introduction}

The emergence of next-generation sequencing (NGS) has changed the paradigm of genetic and genomic sequencing

Correspondence to: Dr Il-Jin Kim or Dr David M. Jablons, Thoracic Oncology Laboratory, Department of Surgery, University of California San Francisco, 2340 Sutter Street, Room N219, San Francisco, CA 94115, USA

E-mail: Il-Jin.Kim@ucsf.edu

E-mail: David.Jablons@ucsf.edu

Key words: next-generation sequencing, mutation, clinical laboratory, cancer, diagnosis studies in personalized medicine. Currently, the power of NGS technology has allowed large scale DNA sequencing projects to be completed in record time, releasing huge amounts of invaluable genetic information. The Cancer Genome Atlas (TCGA) is an international consortium that has sequenced the exome from more than 17,200 tumor patient samples including lung (1-4), colon and rectal (5), breast (6), prostate (7), bladder (8), melanoma (9), gastric adenocarcinoma (10), and numerous other cancer types (11-24). NGS has helped to identify actionable somatic mutations in cancer. Since human cancers are mainly caused by genetic alterations of key drivers or main pathway regulator genes, use of NGS is expected to identify new therapeutic targets and diagnostic markers.

More and more molecular diagnostic laboratories are using NGS to screen mutations of key genes for either drug selection as a targeted therapy or for patient follow-up such as disease recurrence monitoring. The two most common NGS library preparation methods are hybridization or capturing-based (25) and amplicon-based methods (26). Both have proved to work efficiently with DNA extracted from formalin-fixed, paraffinembedded (FFPE) tissue specimens, which account for the vast majority of samples for molecular and histopathology diagnosis. However, several obstacles prevent the routine implementation of NGS technology in the clinical molecular diagnostic setting: the sophisticated sample preparation process, high cost, time-consuming data analyses, as well as the reproducibility and accuracy of interpretation.

Moreover, it is not always feasible to investigate reproducibility and accuracy of sequencing results among different clinical laboratories due to different systems including technician's skill, DNA and RNA extraction, library preparation, library quality and quantity measurement, sequencing and data analyses. Although the same sequencing library and sequencing reagents are used, the results can be different depending on the several factors mentioned above. This can be a huge problem when considering the significance of the sequencing result and its role as treatment selection.

To address those of the potentially important disparities in workflow, we sought to determine the variations and consistencies between two different clinical laboratories when testing a targeted cancer panel comprising 25 cancer driver 
genes known to be clinically relevant. Clinical samples and commercially available mutation-positive DNA were tested for laboratory-to-laboratory consistency, validation of intralaboratory reproducibility, and limit of detection (LOD) analysis. We used both clinical samples and mutation positive DNA control with various types of mutations. We focused on consistency and reproducibility of sequencing results in two different laboratories for the laboratory-to-laboratory accuracy test. We also aimed to test batch-to-batch or person-to-person variations by doing 5 independent sequencings in one laboratory. Finally, we tested the limit of mutation detection by serial dilution of a known mutation-positive DNA sample with a wild-type or non-mutant control sample in a limit of detection test.

\section{Materials and methods}

Experimental design. The experimental design of our targeted NGS cancer panel validation consisted of three different experiments conducted at two independent Clinical Laboratory Improvement Amendments (CLIA)-certified laboratories, Encore Clinical (Brisbane, CA, USA; referred to as Laboratory A) and Purity Laboratories (Lake Oswego, OR, USA; referred to as Laboratory B). The first experiment was laboratory-to-laboratory accuracy validation to determine the reproducibility and accuracy of the targeted NGS panel (NextDaySeq ${ }^{\mathrm{TM}}$ Pan Cancer HotSpot Panel; CureSeq Inc., Brisbane, CA, USA) of 25 genes selected for clinical relevance of various human cancers. The second experiment was intra-laboratory precision validation to determine the consistency of results in multiple independent experiments in one laboratory. To test intra-laboratory reproducibility, five samples were assayed across five independent experiments by two technicians in the Laboratory B. The third experiment was the limit of detection (LOD) test, which measured the lowest level of mutation allele frequency. It was performed by diluting mutated DNA from a sample with a previously known genotype (KRAS mutation) and mutation allele frequency with DNA from a non-mutated (WT) sample on a wide range of dilutions and assayed in Laboratory B.

Formalin-fixed, paraffin-embedded (FFPE) specimens and samples. In the validation of the three tests mentioned above, we used two commercially available FFPE cell lines, with known genotypes and mutation allele frequencies (EGFR and KRAS Gene-Specific Multiplex Reference Standard cell lines; Horizon Discovery, Cambridge, MA, USA; cat no. HD850 and HD301 for EGFR and KRAS, respectively), 48 FFPE or frozen cancer tissues collected under a protocol (\#11-06107) approved by the Committee for Human Research at the University of California, San Francisco, and the AcroMetrix Oncology Hotspot Control DNA (Thermo Fisher Scientific, Waltham, MA, USA; cat. no. 969056) to test multiple mutations across different regions targeted by the NGS panel.

FFPE tissue processing and DNA extraction. For each sample one FFPE tissue section, 5-10 $\mu \mathrm{m}$ in thickness with no more than $2.25 \mathrm{~cm}^{2}$ of tissue area, was used as starting material for DNA extraction with the UltraRapid FFPE DNA extraction kit (CureSeq; cat. no. CS-FFPE-50). Extraction was performed in accordance with the manufacturer's instructions. Briefly, the frosted histological slides containing the FFPE tissue sections were deparaffinized in xylene for $10 \mathrm{~min}$ at room temperature in a dedicated fume hood, followed by complete air dry for at least $10 \mathrm{~min}$. The deparaffinized FFPE tissue was hydrated with $5 \mu 1$ of Solution A (CureSeq) and transferred into a lowbinding $0.2 \mathrm{ml}$ PCR tube containing $70 \mu \mathrm{l}$ of Solution A. The tube was then incubated in a regular thermal cycler for $5 \mathrm{~min}$ at $99^{\circ} \mathrm{C}$. After adding $10 \mu \mathrm{l}$ of resuspended Solution B (CureSeq), samples were incubated for $5 \mathrm{~min}$ at $60^{\circ} \mathrm{C}$ followed by $5 \mathrm{~min}$ at $99^{\circ} \mathrm{C}$. Samples were centrifuged at $1,000 \mathrm{x} \mathrm{g}$ for $1 \mathrm{~min}$ at room temperature, and the supernatant was transferred into a clean tube without disturbing the pellet.

Quality assessment and quantitation of functional DNA concentration by $q P C R$. The quantity and quality control of the extracted DNA was evaluated using the DNA Q\&Q kit (CureSeq; cat. no. Q\&Q-DNA-50) and run on a QuantStudio 6 qPCR platform (Thermo Fisher Scientific), following the manufacturer's instructions. The DNA Q\&Q is a fluorescentbased qPCR assay that provides quantitation of human genomic DNA by measuring the presence of short DNA fragments (amplicons called DS1; length $\leq 85 \mathrm{bp}$ ). The integrity of the extracted DNA is evaluated by calculating the ratio of DNA concentration of short (DS1) and long amplicons (called DS2; length <190 bp). Briefly, the extracted DNA was diluted 1:4 (vol/vol) in molecular biology-grade water. Each sample DNA was tested in triplicate for both DS1 and DS2 assays. The qPCR thermal profile and reagents volume shared for DS1 and DS2 were as follows: $2 \mu 1$ of diluted DNA was mixed with $10 \mu \mathrm{l}$ of 2x PCR Master Mix, $1 \mu \mathrm{l}$ of 20x DS1 or DS2 assay oligonucleotides and $7 \mu \mathrm{l}$ of water. The thermal profile of the qPCR reaction started with an incubation for $2 \mathrm{~min}$ at $50^{\circ} \mathrm{C}$, followed by $2 \mathrm{~min}$ at $95^{\circ} \mathrm{C}$ and $40 \mathrm{qPCR}$ cycles of $15 \mathrm{sec}$ at $95^{\circ} \mathrm{C}$ plus $1 \mathrm{~min}$ at $60^{\circ} \mathrm{C}$. The melting curve consists of a single cycle of $15 \mathrm{sec}$ at $95^{\circ} \mathrm{C}, 1 \mathrm{~min}$ at $60^{\circ} \mathrm{C}$ and a final incubation of $15 \mathrm{sec}$ at $95^{\circ} \mathrm{C}$. ROX was used as passive reference. The thresholds of increase in the fluorescence intensity $(\Delta R n)$ were 1.29 for DS1 and 1.00 for DS2. The analysis of qPCR data was carried out by using the DNA Q\&Q Calculator v7.0 provided by the manufacturer.

Targeted NGS library preparation. The targeted cancer NGS panel (NextDay Seq-Pan Cancer HotSpot Panel kit; CureSeq) was used to prepare the libraries for sequencing in the Ion Torrent PGM sequencer. The libraries were prepared in a three-step protocol. First, $10 \mathrm{ng}$ of DNA was loaded in a multiplexed, high-fidelity PCR reaction, targeting hot-spot mutated loci of the human genome from 25 of the most commonly mutated genes across solid and hematological tumor types (ABL1, AKT1, ALK, BRAF, CTNNB1, DDR2, DNMT3A, EGFR, ERBB2, ESR1, FLT3, GNA11, GNAQ, HRAS, IDH1, IDH2, KRAS, MAP2K1, NRAS, PIK3CA, $P T E N$, RET, SMAD4, SMO and TSC1) and run for 22 cycles. Second, the PCR products were directly ligated to universal adapters and barcodes. Third, the libraries were purified by using a magnetic bead-based protocol and eluted in $30 \mu \mathrm{l}$ of $1 \mathrm{X}$ LTE buffer. The prepared libraries were stored at $4^{\circ} \mathrm{C}$ for short-term and at $-20^{\circ} \mathrm{C}$ for long-term storage. Each library (1 $\mu \mathrm{l}$ ) was loaded into a High Sensitivity DNA chip (Agilent 
Technologies, Santa Clara, CA, USA; cat. no. 5067-4626) to evaluate the quality and library yield. The yield from each library (pmol/l) was calculated by running a smear analysis of the electropherogram peaks ranging from 245 to $400 \mathrm{bp}$, using the Bioanalyzer 2100 platform (Agilent Technologies) and software.

Emulsion PCR and Ion torrent sequencing. Following the manufacturer's instructions, the volume of each of the prepared libraries was adjusted to add equimolar amounts of each library into the emulsion PCR for a final total molarity ranging from 400 to 800 pmoles. The emulsion PCRs were carried out using the Ion PGM Template OT2 200 kit (Thermo Fisher Scientific; cat. no. 4480974) and loaded in the Ion OneTouch ${ }^{\mathrm{TM}} 2$ System, after which non-templated Ion Sphere Particles (ISP) beads were removed by magnetic bead purification (included in the Ion PGM Template OT2 200 kit). After ISP bead enrichment, each library was sequenced using the Ion PGM Sequencing 200 kit V2 (Thermo Fisher Scientific; cat. no. 4482006; lot no. sequencing reagents: 010688; sequencing solution: 010689). The enriched sequencing microreactors from each emulsion PCR were loaded in an Ion 316 v2 Chip or an Ion 318 v2 Chip (Thermo Fisher Scientific; cat no. 4484355; lot no. P32800.1, and P32672.1), and sequenced on an Ion Torrent ${ }^{\mathrm{TM}}$ Personal Genome Machine ${ }^{\circledR}$ (PGM) platform.

Laboratory-to-laboratory accuracy test. Forty-eight FFPE or fresh-frozen cancer tissues, two cancer FFPE cell lines samples (Horizon), and one commercial DNA containing multiple cancer mutations (AcroMetrix) were used for targeted NGS analysis. All the library preparation and sequencing were done in Laboratories A and B.

Intra-laboratory precision test. Four cancer FFPE samples (9T, 14T, 19T and 29T) and one normal tissue (3N) were used for the targeted NGS analysis in Laboratory B. Five independent NGS analyses were done by two technicians using the above mentioned five FFPE samples.

Limit of detection (LOD) validation. The LOD study was done at Laboratory B serially diluting a $K R A S(\mathrm{G} 12 \mathrm{~A})$ mutant FFPE sample (8T) with a KRAS wild-type sample (27T). The DNA from a mutated sample (8T) was serially diluted with WT DNA to create a decreasing mutation allele frequency titration experiment from 70 to $2 \%$.

NGS data analysis. The PGM's default system, the Ion Torrent Suite (ITS) was used for sequencer data management. ITS integrates a cluster of pre-processing algorithms for NGS data, to align the targeted sequencing data against the human reference genome (hg19) and to normalize the quality scores. The output sequencing data for each barcoded library was aligned against the human genome by the Ion Torrent Suite software and compiled into .bam and their indexed counterpart (.bai) files. These files were used to run coverage analysis of targeted regions and variant calls with DanPA software (CureSeq). DanPA software, by default, only calls mutations with allele frequency $>2 \%$. Ion Torrent Suite maximizes the quality of the sequencing data output, filters out the data coming from sequencing microreactors containing polyclonal templates and low quality reads or primer dimers. After the initial filtering of data, the quality of a sequencing run can be assessed by evaluating the percentage of bases with $\geq Q 20$ value, percentage of sequencing reads successfully aligned against the reference human genome, mean of sequencing read length and the median sequencing coverage. The Phred score (Q-score) defines the logarithmic chances that a sequenced nucleotide base is erroneously called, so a base with $\geq \mathrm{Q} 20$ indicates that the error rate is $<1$ in 100 .

Statistical analysis. The mutation allele frequency variable was analyzed as a continuous variable. We calculated the correlation between mutation allele frequencies from Laboratory A and $\mathrm{B}$, or from different experiments from intra-laboratory precision validation, by linear regression analysis (GraphPad Prism v 6.0 software). The reproducibility of each mutation detected in the intra-laboratory validation was calculated by coefficient of variation (GraphPad Prism v 6.0 software). All statistical tests were considered significant when the alpha values were $<0.05$.

\section{Results}

Laboratory-to-laboratory accuracy test. The sequencing data obtained was of high quality and consistent inter- and intra-experimentally in both laboratories. The percentage of sequenced bases with $\geq \mathrm{Q} 20$ value ranged from 88.18 to $91.98 \%$ in Laboratory A and from 89.29 to $92.18 \%$ in Laboratory B. The average of sequencing reads aligned against the reference human genome was $96.00 \%$ for sequencing runs from Laboratory A and $96.75 \%$ for runs from Laboratory B. The median sequencing coverage in targeted regions was of $3,053 \mathrm{X}$ and 3,664X for sequencing runs from Laboratory A and B, respectively.

Among the 48 clinical samples used in the accuracy test, a total of 87 mutations were detected, including $63(72.4 \%)$ silent or synonymous and 24 (27.6\%) non-synonymous variants, respectively. In the Acrometrix control DNA, 83 expected mutations targeted by the NGS library panel were detected, including 7 (8.4\%) silent and 76 (91.6\%) non-synonymous variants. In the two commercial FFPE cell lines, a total of 12 mutations were detected, including $2(16.7 \%)$ silent and $10(83.3 \%)$ non-synonymous variants. Out of a total of 182 mutations, 181 were detected in both laboratories. The study of consistency of mutation calls between both clinical laboratories showed that $99.5 \%$ (181 out 182) of the mutations detected in Laboratory B were also found in Laboratory A. One synonymous mutation (HRAS $\mathrm{H} 27 \mathrm{H}$; mutation allele frequency, $2.4 \%$ ), was detected in sample number 25 in Laboratory B but not detected in Laboratory A. Because silent mutations detected in tumor tissue can be either germline polymorphisms or somatic mutations, and the germline variants can affect the degree of correlation between mutation allele frequencies found in both laboratories, two separated analyses were performed: one for all the variants and another for non-synonymous mutations. The regression analysis of mutation allele frequencies from mutations found in both laboratories showed very strong correlation when all the variants $\left(n=181\right.$; slope $\left.=1.0044 ; \mathrm{R}^{2}=0.996 ; \mathrm{P}<0.0001\right)$ were analyzed and if only non-synonymous mutations were analyzed $(n=110$; 

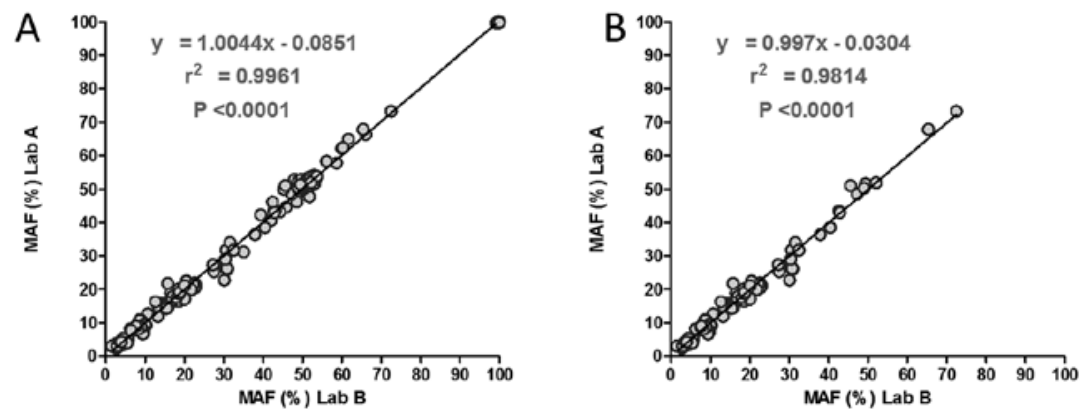

Figure 1. Correlation of mutation allele frequencies obtained at both laboratories. The degree of correlation of mutation allele frequencies obtained in both laboratories was assessed by linear regression analysis for all mutations (panel A; slope $=1.0044 ; \mathrm{R}^{2}=0.9961 ; \mathrm{P}<0.0001 ; \mathrm{n}=182$ ) and only for non-synonymous mutations (panel B; slope $=0.997 ; \mathrm{R}^{2}=0.9814 ; \mathrm{P}<0.0001 ; \mathrm{n}=110$ ). Each point represents one mutation.

Table I. Reproducibility of quality parameters of the five sequencing runs from the intra-laboratory precision test.

\begin{tabular}{lcccccc}
\hline & \multicolumn{3}{c}{$\% \geq Q$ Q20 bases } & & \\
Run name & Median (\%) & Min (\%) & Max (\%) & $\begin{array}{c}(\%) \text { Seq reads } \\
\text { aligned to hg19 }\end{array}$ & $\begin{array}{c}\text { Mean read } \\
\text { length (bp) }\end{array}$ & $\begin{array}{c}\text { Median Seq. coverage } \\
\text { (No. reads) }\end{array}$ \\
\cline { 2 - 4 } Run \#1 & 92.1 & 91.7 & 92.4 & $98 \%$ & 153 & $7,160 \mathrm{x}$ \\
Run \#2 & 91.9 & 91.5 & 92.2 & $98 \%$ & 159 & $6,896 \mathrm{x}$ \\
Run \#3 & 90.7 & 90.1 & 91.1 & $97 \%$ & 148 & $6,752 \mathrm{x}$ \\
Run \#4 & 92.9 & 92.5 & 93.1 & $97 \%$ & 150 & $7,830 \mathrm{x}$ \\
Run \#5 & 92.0 & 91.5 & 92.3 & $98 \%$ & 156 & $7,519 \mathrm{x}$ \\
\hline
\end{tabular}

Median, median percentage of bases with $\geq Q 20$ value; Min, minimum percentage of bases with $\geq Q 20$ value; Max, maximum percentage of bases with $\geq Q 20$ value.

Table II. Quantitative and qualitative reproducibility of mutation calls from the intra-laboratory precision test.

\begin{tabular}{|c|c|c|c|c|c|c|c|c|c|}
\hline $\begin{array}{l}\text { Sample } \\
\text { ID }\end{array}$ & Mutation ID & $\begin{array}{l}\text { Mut. Allele } \\
\text { Freq. Exper. } \\
\text { \#1 }\end{array}$ & $\begin{array}{c}\text { Mut. Allele } \\
\text { Freq. Exper. } \\
\# 2\end{array}$ & $\begin{array}{c}\text { Mut. Allele } \\
\text { Freq. Exper. } \\
\# 3\end{array}$ & $\begin{array}{c}\text { Mut. Allele } \\
\text { Freq. Exper. } \\
\text { \#4 }\end{array}$ & $\begin{array}{c}\text { Mut. Allele } \\
\text { Freq. Exper. } \\
\text { \#5 }\end{array}$ & $\begin{array}{l}\text { Mut. Allele } \\
\text { Freq. AVR }\end{array}$ & $\begin{array}{l}\text { Mut. Allele } \\
\text { Freq. SD }\end{array}$ & $\begin{array}{l}\text { Mut. Allele } \\
\text { Freq. CV } \\
(\%)\end{array}$ \\
\hline \multirow[t]{2}{*}{3} & EGFR p.Q787Q & 51.09 & 49.22 & 50.25 & 49.80 & 51.84 & 50.44 & 1.04 & 2.06 \\
\hline & HRAS p.H27H & 52.61 & 49.12 & 51.45 & 52.06 & 52.11 & 51.47 & 1.38 & 2.67 \\
\hline \multirow[t]{3}{*}{9} & EGFR p. & 48.04 & 47.69 & 47.03 & 48.16 & 45.65 & 47.31 & 1.03 & 2.17 \\
\hline & E746_A750delELREA & & & & & & & & \\
\hline & HRAS p.H27H & 48.74 & 50.58 & 50.19 & 51.33 & 50.94 & 50.35 & 1.00 & 1.98 \\
\hline \multirow[t]{2}{*}{14} & EGFR p.Q787Q & 99.80 & 99.88 & 99.84 & 99.95 & 99.97 & 99.89 & 0.07 & 0.07 \\
\hline & KRAS p.G12V & 39.00 & 37.60 & 39.81 & 40.27 & 37.42 & 38.82 & 1.28 & 3.30 \\
\hline \multirow[t]{3}{*}{19} & EGFR p.Q787Q & 99.63 & 99.81 & 99.88 & 99.81 & 99.81 & 99.79 & 0.09 & 0.09 \\
\hline & HRAS p.H27H & 41.81 & 41.69 & 40.68 & 42.56 & 41.71 & 41.69 & 0.67 & 1.60 \\
\hline & KRAS p.G12V & 21.74 & 22.48 & 23.53 & 22.93 & 22.25 & 22.59 & 0.68 & 3.00 \\
\hline \multirow[t]{3}{*}{29} & EGFR p.Q787Q & 47.80 & 50.65 & 50.86 & 53.72 & 53.48 & 51.30 & 2.42 & 4.72 \\
\hline & HRAS p.H27H & 55.64 & 53.66 & 52.28 & 55.81 & 55.79 & 54.64 & 1.60 & 2.93 \\
\hline & PIK3CA p.H1047R & 20.20 & 21.80 & 20.70 & 20.47 & 21.60 & 20.96 & 0.71 & 3.37 \\
\hline
\end{tabular}

Exper, experiment; AVR, average; SD, standard deviation; CV (\%), percentage of coefficient of variation.

slope $\left.=0.997 ; \mathrm{R}^{2}=0.9814 ; \mathrm{P}<0.0001\right)$ (Fig. 1). Examples of detected mutations in the two laboratories are shown in Fig. 2.

The laboratory-to-laboratory accuracy test showed a sensitivity of $100 \%$ (95\% CI, $92.45-100 \%$ ), specificity of $99.97 \%$ (95\% CI, 99.85-100\%), positive predictive value of $97.9 \%$ (95\%
CI, 88.93-99.95\%) and a negative predictive value of $100 \%$ (95\% CI, 99.90-100\%).

Intra-laboratory precision test. The quality parameters of the intra-laboratory precision test showed high reproduc- 
A
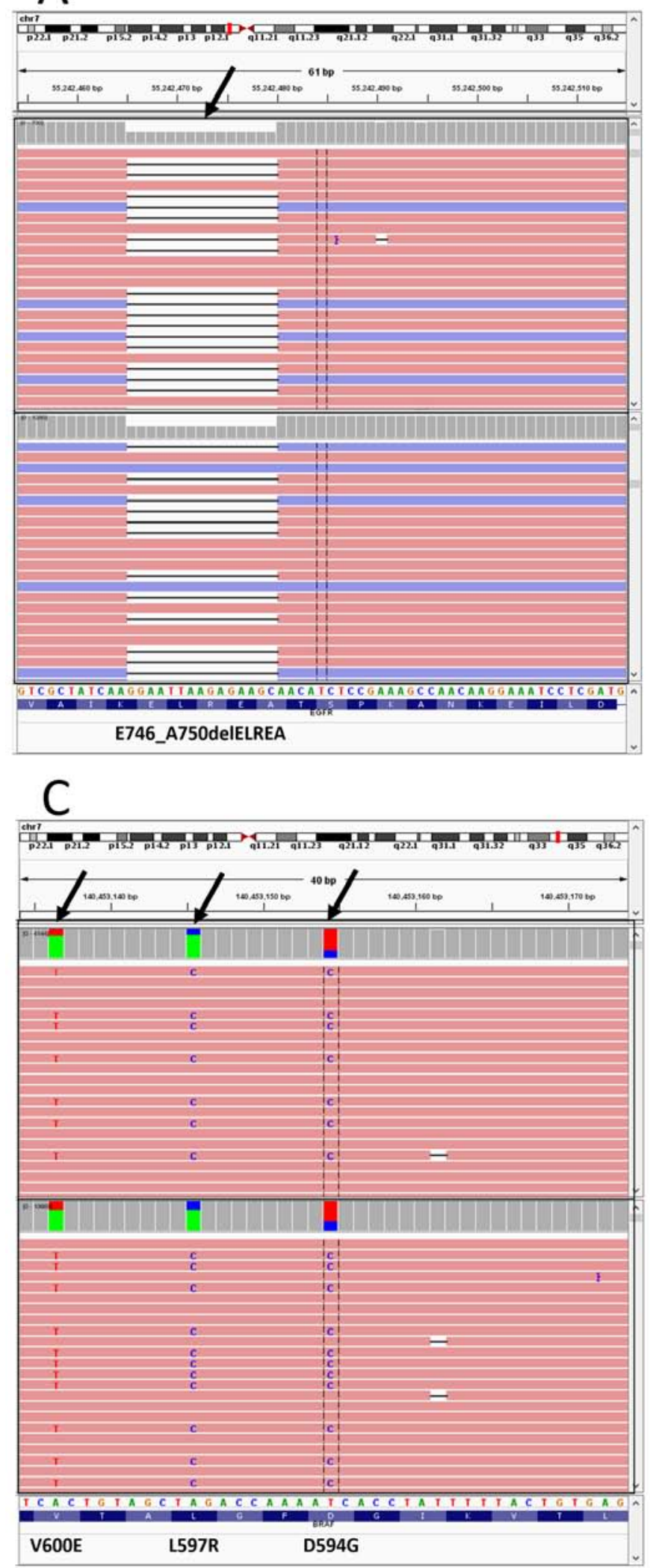

B

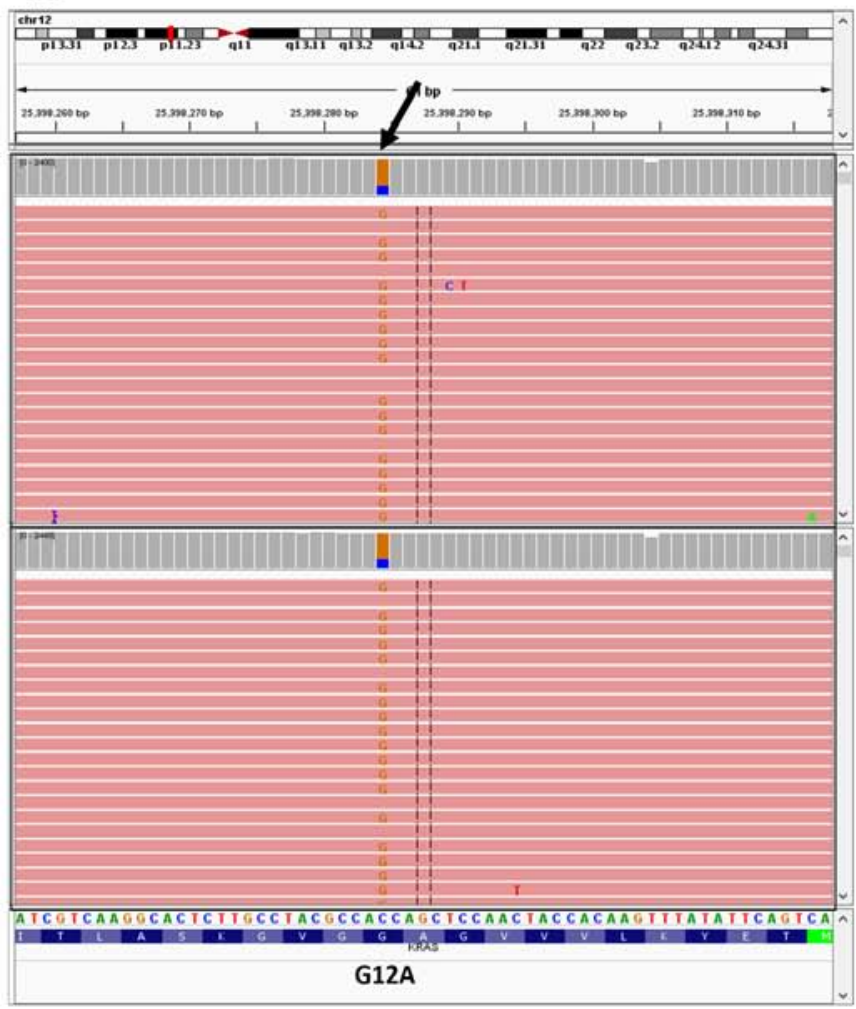

D

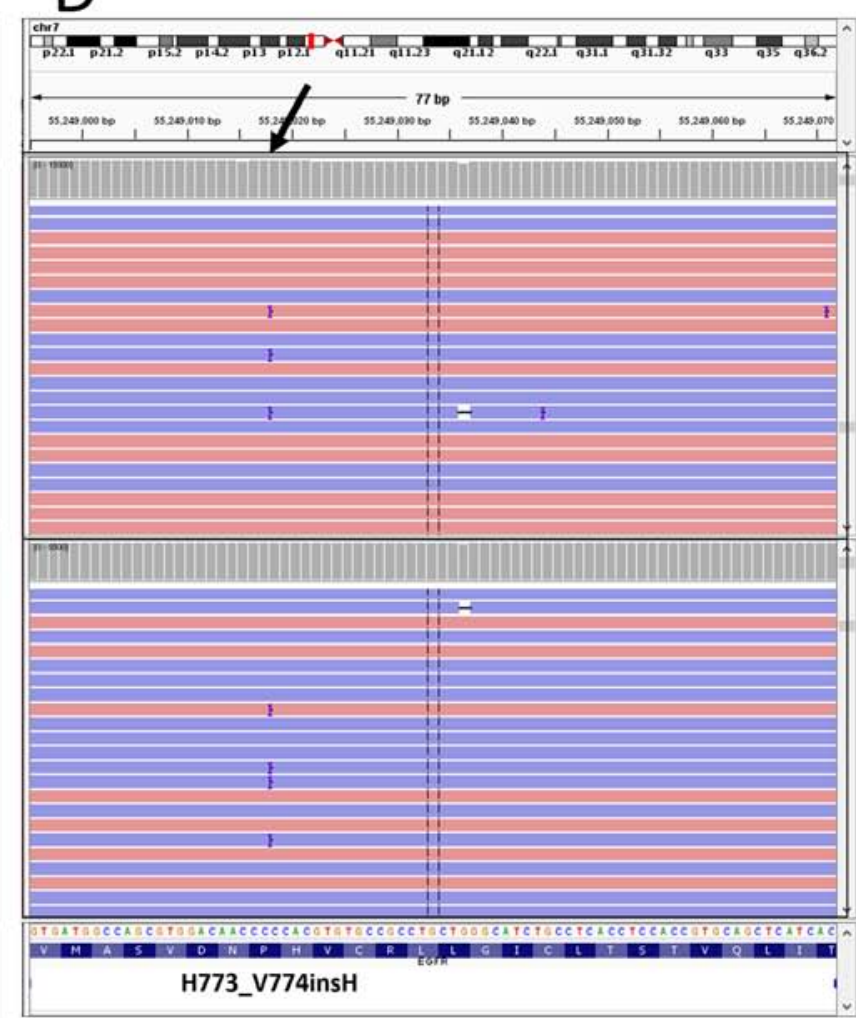

Figure 2. Representative mutations detected in a laboratory-to-laboratory accuracy test. Images at specific mutation loci were taken using IGV software from sequencing output (bam and bai) files. Each panel is composed of an upper track of the sequencing result at Laboratory A and a lower track of the sequencing result at Laboratory B. (A) EGFR exon 19 deletion (E746_A750delELREA). (B) KRAS G12A missense mutation. (C) Multiple mutations in exon 15 of BRAF (V600E; L597R; D594G) from Acrometrix control DNA. (D) H773_V774insH insertion mutation at exon 20 of EGFR. Mutations are shown with arrows.

ibility (Table I). Regarding the mutational data, DanPA software detected the same mutation in all five samples across the five independent experiments, showing $100 \%$ qualitative reproducibility. Quantitatively, the intra-labo- 

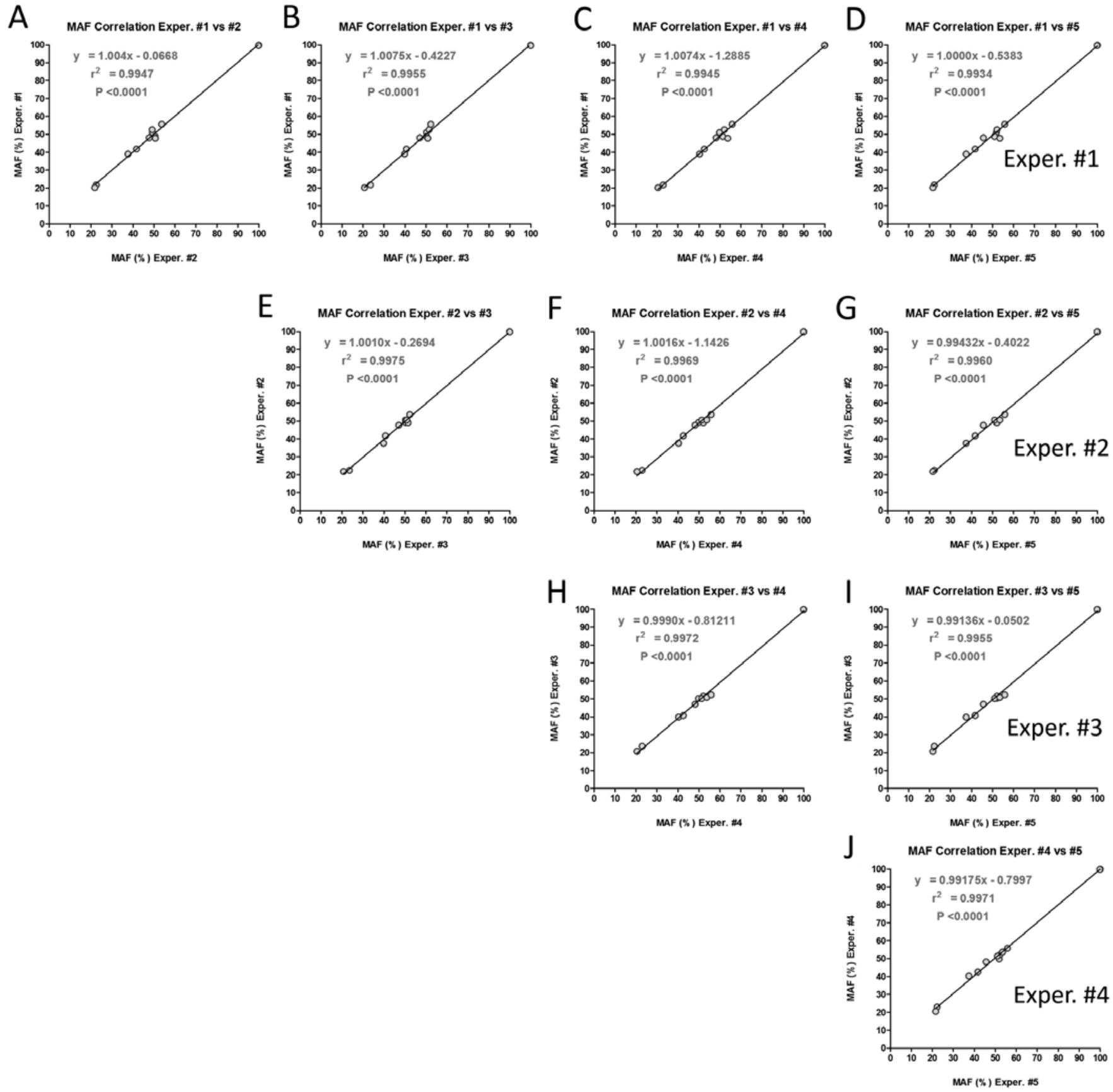

Figure 3. Correlation of mutation allele frequencies obtained in the intra-laboratory precision validation experiment. The degree of correlation of the twelve mutations detected in the five samples across the five independent experiments was assessed by regression analysis. All the possible combinations of data sets from different experiments are represented in a matrix graph as follows: panel A (mutation allele frequency from experiment \#1 vs. mutation allele frequency from experiment \#2), panel B (experiment \#1 vs. \#3), panel C (experiment \#1 vs. \#4), panel D (experiment \#1 vs. \#5), panel E (experiment \#2 vs. \#3), panel F (experiment \#2 vs. \#4), panel G (experiment \#2 vs. \#5), panel H (experiment \#3 vs. \#4), panel I (experiment \#3 vs. \#5), panel J (experiment \#4 vs. \#5). Each point represents one mutation. All the combinations showed a strong correlation.

ratory reproducibility was very high, as the coefficient of variation of the mutation allele frequency for each mutation across the five independent experiments was always $<5 \%$ (Table II), regardless of whether the variant was silent or non-synonymous. The regression analysis of mutation allele frequencies found in the five different experiments were highly correlated (Fig. 3).

Limit of detection validation. The LOD experiment was run in the Laboratory B. All the different serial dilutions of the
$K R A S$ mutant sample in KRAS WT DNA were run in the same experiment. The quality of the sequencing data was comparable to that from the laboratory-to-laboratory and intra-laboratory validations. The percentage of sequenced bases with $\geq Q 20$ value ranged from 89.14 to $90.58 \%$. More than $97 \%$ of the sequencing reads were successfully aligned against the reference human genome. The median sequencing coverage in targeted regions was of $6,350 \mathrm{X}$ reads.

The KRAS G12A mutation assayed for LOD was successfully detected at 71.1, 60.8, 41.2, 27.6, 13.3, 6.5, 4.1 and 2.0\% 
Table III. Results of the limit of detection (LOD) validation.

\begin{tabular}{|c|c|c|c|c|c|c|c|c|c|c|}
\hline $\begin{array}{l}\text { Sequencing } \\
\text { barcode \# }\end{array}$ & $\begin{array}{l}\text { Experimental } \\
\text { condition }\end{array}$ & $\begin{array}{c}\text { Gene } \\
\text { symbol }\end{array}$ & $\begin{array}{c}\text { Cosmic } \\
\text { mutation ID }\end{array}$ & $\begin{array}{l}\text { CDS variant } \\
\text { coordinates }\end{array}$ & $\begin{array}{c}\text { Protein } \\
\text { variant } \\
\text { coordinates }\end{array}$ & Chr \# & Exon & $\begin{array}{l}\text { No. of } \\
\text { mutation } \\
\text { reads }\end{array}$ & $\begin{array}{l}\text { No. of } \\
\text { WT } \\
\text { reads }\end{array}$ & $\begin{array}{c}\text { (\%) Mut. } \\
\text { Allele } \\
\text { Freq. }\end{array}$ \\
\hline 8 & WT & \multicolumn{9}{|c|}{ No mutation detected } \\
\hline 16 & Mutated & KRAS & COSM522 & c. $35 \mathrm{G}>\mathrm{C}$ & p.G12A & $\operatorname{chr} 12$ & KRAS_Exon_2 & 7896 & 3213 & 71.08 \\
\hline 9 & Condition \#1 & KRAS & COSM522 & c. $35 \mathrm{G}>\mathrm{C}$ & p.G12A & $\operatorname{chr} 12$ & KRAS_Exon_2 & 2781 & 1794 & 60.79 \\
\hline 10 & Condition \#2 & KRAS & COSM522 & c. $35 \mathrm{G}>\mathrm{C}$ & p.G12A & $\operatorname{chr} 12$ & KRAS_Exon_2 & 1318 & 1862 & 41.45 \\
\hline 11 & Condition \#3 & KRAS & COSM522 & c. $35 \mathrm{G}>\mathrm{C}$ & p.G12A & $\operatorname{chr} 12$ & KRAS_Exon_2 & 1265 & 3319 & 27.60 \\
\hline 12 & Condition \#4 & KRAS & COSM522 & c. $35 \mathrm{G}>\mathrm{C}$ & p.G12A & $\operatorname{chr} 12$ & KRAS_Exon_2 & 957 & 6231 & 13.31 \\
\hline 13 & Condition \#5 & KRAS & COSM522 & c. $35 \mathrm{G}>\mathrm{C}$ & p.G12A & $\operatorname{chr} 12$ & KRAS_Exon_2 & 213 & 3062 & 6.50 \\
\hline 14 & Condition \#6 & KRAS & COSM522 & c. $35 \mathrm{G}>\mathrm{C}$ & p.G12A & $\operatorname{chr} 12$ & KRAS_Exon_2 & 219 & 5129 & 4.09 \\
\hline 15 & Condition \#7 & KRAS & COSM522 & c. $35 \mathrm{G}>\mathrm{C}$ & p.G12A & $\operatorname{chr} 12$ & KRAS_Exon_2 & 87 & 4260 & 2.00 \\
\hline
\end{tabular}

CDS, coding DNA sequence; $\mathrm{Chr}$ \#, chromosome number.

mutation allele frequencies, but not in the WT DNA sample, at which the findings ensure the reliability of the data (Table III).

\section{Discussion}

Our comparison study of a targeted NGS panel shows data quality and accuracy is very high and satisfactory within and between two clinical laboratories. In the present study, we first conducted a laboratory-to-laboratory accuracy test experiment because reproducibility of a mutation or a variant calling is the basic but the most important factor to be considered for molecular genetic testing in a clinical laboratory. We found that Laboratory B detected 182 synonymous or non-synonymous mutations in a total of 51 samples and that Laboratory A detected 181. One variant calling was not concordant. Our check of the raw sequencing data using a data analysis program and an Integrative Genomics Viewer (IGV; https://www.broadinstitute.org/igv/) showed there was no single mutant read in the data from Laboratory A. The discordant mutation has a low frequency of the mutant allele: $2.4 \%$. This suggests challenging samples with a low minor allele frequency (MAF) must be interpreted carefully. We also did a coverage comparison between two laboratories' results. Although correct mutation detection would be the most important factor for doing NGS analysis, we questioned the consistency of the percentage of mutant alleles in both laboratories. Regression analysis showed a very high correlation of MAF from all the common mutations found in both laboratories $\left(n=110\right.$; slope $\left.=0.997 ; \mathrm{R}^{2}=0.9814 ; \mathrm{P}<0.0001\right)$. The accuracy test result indicates that mutation calling is stable and reliable in two laboratories.

The results of the second test, an intra-laboratory precision test in which we analyzed the outcome of two technicians performing five independent experiments in one laboratory, showed that even in the same clinical laboratory, variations among technicians and reagents or kits could be significant. Thus, intra-laboratory precision validation is important for checking variations caused by batch-to-batch or personto-person effects. In our experiment, all the variants were detected correctly in five tests (100\% reproducibility). The coefficient of variation of the mutation allele frequency across the five independent experiments was $<5 \%$.

Our third experiment, a limit of detection (LOD) test, examined the stability of mutation calling in different proportion of tumor part or mutant alleles. We serially diluted a KRAS G12A mutant sample with the $K R A S$ wild-type DNA from $\sim 70 \%$ to finally $2 \%$ mutation allele frequency. We set the cut-off level for mutation detection at $2 \%$ because we believe a mutation candidate with a mutation allele frequency less than $2 \%$ has questionable clinical relevance and technical reliability. We limited our scope to regular FFPE tumor or biopsy specimens and aimed to provide coverage of a few hundreds to thousands of reads for selected genes or amplicons. Thus, we believe our cut-off level, $2 \%$ in mutation allele frequency, is the minimal and reasonable level for mutation detection. We also selected $K R A S$ mutant for the LOD test sample because KRAS is one of the most frequently mutated genes in various human cancers. In the present study, KRAS G12A mutation was detected in all diluted samples, from 70 through $2 \%$. These findings suggest that most of the FFPE cancer samples with a tumor proportion of at least 10-20\% would be suitable for targeted NGS analysis, although screening is always encouraged for samples with a tumor proportion $>20 \%$.

Although we believe the consistent results across all three tests are enough to evaluate a targeted NGS cancer panel for most of the clinical samples analyzed in clinical laboratories, several issues remain. First, we tested only FFPE samples and set the cut-off level as $2 \%$ of mutation allele frequency. Liquid biopsy or circulating tumor DNA (ctDNA) is becoming popular for early detection of cancer (27) or monitoring tumor recurrence (28). For liquid biopsy specimens, the sequencing coverage should be much higher and the cut-off level should be much lower than for regular tumor specimens. It is therefore important to systemically analyze liquid biopsy specimens in clinical laboratories. Second, we tested tumor specimens with a tumor proportion $>20 \%$ except for the serial dilution experiment of the LOD test. Many samples from clinics have a tumor proportion $<10-20 \%$ and tend to be rejected by clinical laboratories or analyzed without thorough consideration. It will be important to have a consensus not only for the clinical 
meaning but also technical reliability for such samples. Third, tumor heterogeneity or tumor clonal evolution should also be considered when NGS results are interpreted. If multiple different tumor sites from one slide are analyzed separately or a low mutation allele frequency is considered with a very deep sequencing (i.e. more than 10,000X), this issue should be discussed for its clinical meaning before providing a result to cancer patients. Last, more technical aspects beyond NGS should also be thoroughly checked in a clinical laboratory such as DNA extraction methods, storage time or condition of FFPE blocks or slides.

In conclusion, we believe that this present study, done in compliance with the guidelines of American College of Medical Genetics, demonstrates the feasibility of clinical implementation of a targeted NGS cancer panel analysis for personalized medicine.

\section{Acknowledgements}

The present study was supported by funds from the CureSeq Inc., and the Thoracic Oncology Laboratory at University of California San Francisco (UCSF). DJM and IJK are equity holders and consultants of CureSeq Inc. We thank Pamela Derish in the UCSF Department of Surgery for editorial assistance with the manuscript.

\section{References}

1. Cancer Genome Atlas Research Network: Comprehensive molecular profiling of lung adenocarcinoma. Nature 511: 543-550, 2014

2. George J, Lim JS, Jang SJ, Cun Y, Ozretić L, Kong G, Leenders F, Lu X, Fernández-Cuesta L, Bosco G, et al: Comprehensive genomic profiles of small cell lung cancer. Nature 524: 47-53, 2015.

3. Govindan R, Ding L, Griffith M, Subramanian J, Dees ND, Kanchi KL, Maher CA, Fulton R, Fulton L, Wallis J, et al: Genomic landscape of non-small cell lung cancer in smokers and never-smokers. Cell 150: 1121-1134, 2012.

4. Hammerman PS, Lawrence MS, Voet D, Jing R, Cibulskis K, Sivachenko A, Stojanov P, McKenna A, Lander ES, Gabriel S, et al; Cancer Genome Atlas Research Network: Comprehensive genomic characterization of squamous cell lung cancers. Nature 489: 519-525, 2012.

5. Network TCGA; Cancer Genome Atlas Network: Comprehensive molecular characterization of human colon and rectal cancer. Nature 487: 330-337, 2012.

6. Cancer Genome Atlas Network: Comprehensive molecular portraits of human breast tumours. Nature 490: 61-70, 2012.

7. Abstract $\mathrm{G}$ and Brief I; Cancer Genome Atlas Research Network: The Molecular Taxonomy of Primary Prostate Cancer. Cell 163: $1011-1025,2015$

8. Cancer Genome Atlas Research Network: Comprehensive molecular characterization of urothelial bladder carcinoma. Nature 507: 315-322, 2014.

9. Hodis E, Watson IR, Kryukov GV, Arold ST, Imielinski M, Theurillat JP, Nickerson E, Auclair D, Li L, Place C, et al: A landscape of driver mutations in melanoma. Cell 150: 251-263, 2012.

10. Bass AJ, Thorsson V, Shmulevich I, Reynolds SM, Miller M, Bernard B, Hinoue T, Laird PW, Curtis C, Shen H, Weisenberger DJ, et al; Cancer Genome Atlas Research Network: Comprehensive molecular characterization of gastric adenocarcinoma. Nature 513: 202-209, 2014.

11. Andersson AK, Ma J, Wang J, Chen X, Gedman AL, Dang J, Nakitandwe J, Holmfeldt L, Parker M, Easton J, et al; St. Jude Children's Research Hospital-Washington University Pediatric Cancer Genome Project: The landscape of somatic mutations in infant MLL-rearranged acute lymphoblastic leukemias. Nat Genet 47: 330-337, 2015 .
12. Brennan CWW, Verhaak RGWGW, McKenna A, Campos B, Noushmehr H, Salama SR, Zheng S, Chakravarty D, Sanborn JZ, Berman SH, et al; TCGA Research Network: The somatic genomic landscape of glioblastoma. Cell 155: 462-477, 2013.

13. Cancer Genome Atlas Research Network: Genomic and epigenomic landscapes of adult de novo acute myeloid leukemia. N Engl J Med 368: 2059-2074, 2013.

14. Cancer T and Atlas G; Cancer Genome Atlas Research Network: Integrated genomic analyses of ovarian carcinoma. Nature 474: 609-615, 2011.

15. Chan-On W, Nairismägi M-L, Ong CK, Lim WK, Dima S, Pairojkul C, Lim KH, McPherson JR, Cutcutache I, Heng HL, et al: Exome sequencing identifies distinct mutational patterns in liver fluke-related and non-infection-related bile duct cancers. Nat Genet 45: 1474-1478, 2013.

16. Chen K, Yang D, Li X, Sun B, Song F, Cao W, Brat DJ, Gao Z, $\mathrm{Li} \mathrm{H}$, Liang $\mathrm{H}$, et al: Mutational landscape of gastric adenocarcinoma in Chinese: Implications for prognosis and therapy. Proc Natl Acad Sci USA 112: 1107-1112, 2015.

17. Johnson BE, Mazor T, Hong C, Barnes M, Aihara K, McLean CY, Fouse SD, Yamamoto S, Ueda H, Tatsuno K, et al: Mutational analysis reveals the origin and therapy-driven evolution of recurrent glioma. Science 343: 189-193, 2014.

18. Jones DTW, Jäger N, Kool M, Zichner T, Hutter B, Sultan M, Cho YJ, Pugh TJ, Hovestadt V, Stütz AM, et al: Dissecting the genomic complexity underlying medulloblastoma. Nature 488: 100-105, 2012.

19. Lawrence MS, Sougnez C, Lichtenstein L, Cibulskis K, Lander E, Gabriel SB, Getz G, Ally A, Balasundaram M, Birol I, et al; Cancer Genome Atlas Network: Comprehensive genomic characterization of head and neck squamous cell carcinomas. Nature 517: 576-582, 2015.

20. Li M, Zhang Z, Li X, Ye J, Wu X, Tan Z, Liu C, Shen B, Wang XA, $\mathrm{Wu} \mathrm{W}$, et al: Whole-exome and targeted gene sequencing of gallbladder carcinoma identifies recurrent mutations in the ErbB pathway. Nat Genet 46: 872-876, 2014

21. Lin DC, Hao JJ, Nagata Y, Xu L, Shang L, Meng X, Sato Y, Okuno Y, Varela AM, Ding LW, et al: Genomic and molecular characterization of esophageal squamous cell carcinoma. Nat Genet 46: 467-473, 2014.

22. Lohr JG, Stojanov P, Carter SL, Cruz-Gordillo P, Lawrence MS, Auclair D, Sougnez C, Knoechel B, Gould J, Saksena G, et al; Multiple Myeloma Research Consortium: Widespread genetic heterogeneity in multiple myeloma: Implications for targeted therapy. Cancer Cell 25: 91-101, 2014.

23. Creighton CJ, Morgan M, Gunaratne PH, Wheeler DA, Gibbs RA, Gordon Robertson A, Chu A, Beroukhim R, Cibulskis K, Signoretti S, et al; Cancer Genome Atlas Research Network: Comprehensive molecular characterization of clear cell renal cell carcinoma. Nature 499: 43-49, 2013.

24. Tirode F, Surdez D, Ma X, Parker M, Le Deley MC, Bahrami A, Zhang Z, Lapouble E, Grossetête-Lalami S, Rusch M, et al; St. Jude Children's Research Hospital-Washington University Pediatric Cancer Genome Project and the International Cancer Genome Consortium: Genomic landscape of Ewing sarcoma defines an aggressive subtype with co-association of STAG2 and TP53 mutations. Cancer Discov 4: 1342-1353, 2014.

25. Carrick DM, Mehaffey MG, Sachs MC, Altekruse S, Camalier C, Chuaqui R, Cozen W, Das B, Hernandez BY, Lih CJ, et al: Robustness of next generation sequencing on older formalinfixed paraffin-embedded tissue. PLoS One 10: e0127353, 2015.

26. Fujita S, Masago K, Takeshita J, Okuda C, Otsuka K, Hata A, Kaji R, Katakami N and Hirata Y: Validation of an ion torrent sequencing platform for the detection of gene mutations in biopsy specimens from patients with non-small-cell lung cancer. PLoS One 10: e0130219, 2015.

27. Newman AM, Bratman SV, To J, Wynne JF, Eclov NC, Modlin LA, Liu CL, Neal JW, Wakelee HA, Merritt RE, et al: An ultrasensitive method for quantitating circulating tumor DNA with broad patient coverage. Nat Med 20: 548-554, 2014.

28. Dawson SJ, Tsui DWY, Murtaza M, Biggs H, Rueda OM, Chin SF, Dunning MJ, Gale D, Forshew T, Mahler-Araujo B, et al: Analysis of circulating tumor DNA to monitor metastatic breast cancer. N Engl J Med 368: 1199-1209, 2013. 